\title{
A CASE STUDY OF MONITORING MAIZE DYNAMICS IN SERBIA BY UTILIZING SENTINEL-1 DATA AND GROWING DEGREE DAYS
}

\author{
M. Pandžić ${ }^{1, *}$, N. Ljubičić ${ }^{1}$, G. Mimić ${ }^{1}$, J. Pandžić $^{2}$, B. Pejak ${ }^{1}$, V. Crnojević1 ${ }^{1}$ \\ ${ }^{1}$ University of Novi Sad, BioSense Institute, 21000 Novi Sad, Serbia - (milos.pandzic, natasa.ljubicic, gordan.mimic, \\ branislav.pejak, crnojevic)@biosense.rs \\ ${ }^{2}$ University College of Professional Studies for Civil Engineering and Geodesy, 11000 Belgrade, Serbia - jelenapandzic@vggs.rs
}

Commission III, WG III/2

KEY WORDS: Sentinel-1, Growing Degree Days, Growth Stages, Backscatter, Maize

\begin{abstract}
:
Due to great significance of maize for Serbian agricultural production, maize growth monitoring during the season is highly important. Some of the growth stages have particular influence on the final yield and without optimal conditions at that point, yield losses may be substantial. Hence, it is crucial to be familiar with transition periods between the stages. Sentinel-1 Synthetic Aperture Radar (SAR) data is a reliable source of information for monitoring various crops in all climatic conditions. Dense time series of radar images offer a unique insight into vegetation dynamics during the season. By combining these with the Growing Degree Days (GDD) method that exploits temperature information in order to position different growth stages in time, more precise estimates of crucial periods in maize development can be made. An experiment was conducted for several maize fields in Serbia for 2017 and 2018 season. GDD estimates were constructed based on literature search and temperature information acquired from the Copernicus Climate Change Service. Despite seasonal weather differences, similar trends in radar backscatter were noticeable and existence of certain growth stages (such as emergence, tasselling, silking and physiological maturity) could be estimated. However, these estimates came up with an uncertainty caused most likely by rain and uneven development of maize that influence radar backscatter. The results were compared with estimates made by an agronomy expert that were not based on field inspection but solely on professional experience due to post-seasonal experiment design. The procedure proved to be practical and applicable all over the world.
\end{abstract}

\section{INTRODUCTION}

Maize (Zea mays L.) is one of the major crops in Serbian agricultural production. It is used both for human and livestock diet. According to a report issued in 2019, 962,083 ha in Serbia were sown with maize (Statistical Office of the Republic of Serbia, 2019a). Achieved average yield per ha was 7,797 kg, which resulted in total production of 7.5 million tons of maize. When compared with 2018 results, production in 2019 increased by $7.7 \%$. Average purchase price for maize in 2019 up to August was $15.03 \mathrm{RSD} / \mathrm{kg}$ (RSD stands for Serbian dinar - official currency of the Republic of Serbia), which is about 0.13 EUR $/ \mathrm{kg}$ (Statistical Office of the Republic of Serbia, $2019 b$ ). Maize is also one of the most important goods that Serbian export relies on. Namely, 1.69 million tons and 1.32 million tons were exported in 2017 and 2018, with a total value of 314.6 and 266.7 million USD, respectively (Statistical Office of the Republic of Serbia, 2019b).

In a rapidly changing environment that is striking the whole planet, timely and accurate information on crop performance throughout growing season is highly important to ensure reliable food resources. Monitoring crop production on a global and regional scale is nowadays facilitated with the emergence of novel technologies that include satellites as platforms carrying different sensors. Optical sensors have been in use for a long period, but microwave sensors and Synthetic Aperture Radar (SAR) technologies are gaining more and more attention. The most prominent advantage of radar satellite sensors over optical ones is their weather independence, meaning that their signal can penetrate clouds, which are big obstacle when using optical images. The recent launch of RADARSAT Constellation Mission (RCM), Sentinel-1 and other radar missions confirmed the necessity for SAR technology. While RCM is dedicated to tackle challenges in Canada and has restricted access to its data, Sentinel-1 is intended for use by worldwide audience at no cost.

Due to physical principles of microwaves, when talking about vegetation, radar backscatter is mostly affected by the size, orientation and shape of the plants and their leaves, as well as by the water content of vegetation. This was confirmed with previously conducted experiments reported in the literature. As pointed out by several authors, remote sensing data provides timely and accurate information about vegetation phenological status and its development (Veloso et al., 2017), which are vital cognitions for crop monitoring. Veloso et al. (2017) observed various crops, including maize, with Sentinel-1 SAR and other optical sensors and concluded that SAR data sources accurately reproduce crop growth cycles. Vreugdenhil et al. (2018) analyzed sensitivity of Sentinel-1 backscatter to crop dynamics in Austria and found high exponential correlation of radar signal with Vegetation Water Content (VWC), biomass, Leaf Area Index (LAI) and plant height, with $\mathrm{R}^{2}$ being $0.87,0.85,0.78$ and 0.83 , respectively. Considering only plant height, higher correlation coefficients with SAR backscatter signal were achieved in an early stage of maize growth as opposed to later development stages, which was reported in (Abdikan et al., 2018) and (Liao et al., 2018). In the case study for the Netherlands, Khabbazan et al. (2019) concluded that the structural and biomass changes of crops during the growing season influence the backscatter signal, which is in accordance with previous findings. They estimated emergence and closure dates with high success rates by fitting polynomial functions to the backscatter time series, but estimating a harvesting date turned out to be more challenging. 
Growing Degree Days (GDD) method has its roots dating back to over two and a half centuries ago (Wang, 1960). Long since, air temperature has been recognized as an important factor in crop development and numerous research attempts in the past tried to investigate its impact on maize (e.g. Gilmore Jr. and Rogers, 1958; Cross and Zuber, 1972; Nield and Seeley, 1977). GDD method utilizes only daily minimum and maximum temperature in order to distinguish between different growth stages of crops during the growing season. This makes it handy, but the critics argue since it does not take into account other environmental factors that influence plant growth (Wang, 1960). For this reason, researchers must take caution when exploiting this method.

This paper describes a first attempt of utilizing Sentinel-1 data for monitoring maize dynamics in Serbia together with Growing Degree Days (GDD) technique. The main goal was to estimate their suitability for distinguishing between different growth stages using solely dense time series of radar backscatter and weather information. Scarce ground truth and auxiliary data in this experiment, as a result of post-seasonal experiment design, might be taken as flaws, but the procedure still represents a pragmatic approach to solving real life problems because information on crop development performance is rarely recorded by farmers and available aside from organized trials. Thus, analysis may be difficult, yet more valuable.

\section{TEST SITE}

The study was carried out on maize fields during two successive growing seasons of 2017 and 2018. The test area was located in Vojvodina, the northern part of Serbia, near the city of Bačka Topola. Parcels were distributed in the zone of $10 \mathrm{~km}$ around the point $45^{\circ} 51^{\prime} 00^{\prime \prime} \mathrm{N} 19^{\circ} 27^{\prime} 00^{\prime \prime} \mathrm{E}$ (Figure 1). There were total of 15 parcels for both seasons, out of which 7 for the season 2017 and 8 for 2018. The average size of investigated parcels was about 60 ha and they represented commercial fields owned and managed by a private company. This region is characterized by chernozem soil type (black soil), which is classified as automorphic soil, with favourable air and thermal regime. The climate of Vojvodina is continental moderate, featuring cold winters and hot and humid summers with huge range of extreme temperatures and nonequal distribution of rainfall per months (Hrnjak et al., 2014). The present investigation encompassed years with different temperatures and precipitation sums during maize growing season.

\subsection{Environmental conditions description}

During the maize vegetation period from 1 April to 30 September 2017, the precipitation sum of about $310 \mathrm{~mm}$ was recorded, which was $20 \%$ below the multiyear average. Looking into more details, in April 2017, during maize planting, optimum temperatures accompanied by optimum rainfall amount and distribution were recorded. Temperature conditions in May were appropriate for the initial stages of maize development. At the end of May, higher precipitation amount compared with multiyear average was observed producing favourable environmental conditions for intensive development of maize. In June 2017, air temperatures exceeded multiyear average value. At the same time soil moisture declined rapidly due to the low rainfall amount, which, combined with the aforementioned extremely high temperatures, negatively affected plants during the stage of intensive development. This significantly hot and dry weather continued through July and August as well. High temperatures and lack of rainfall during the first half of July accelerated maize development stages, from tasselling to kernel development and grain filling. Such high

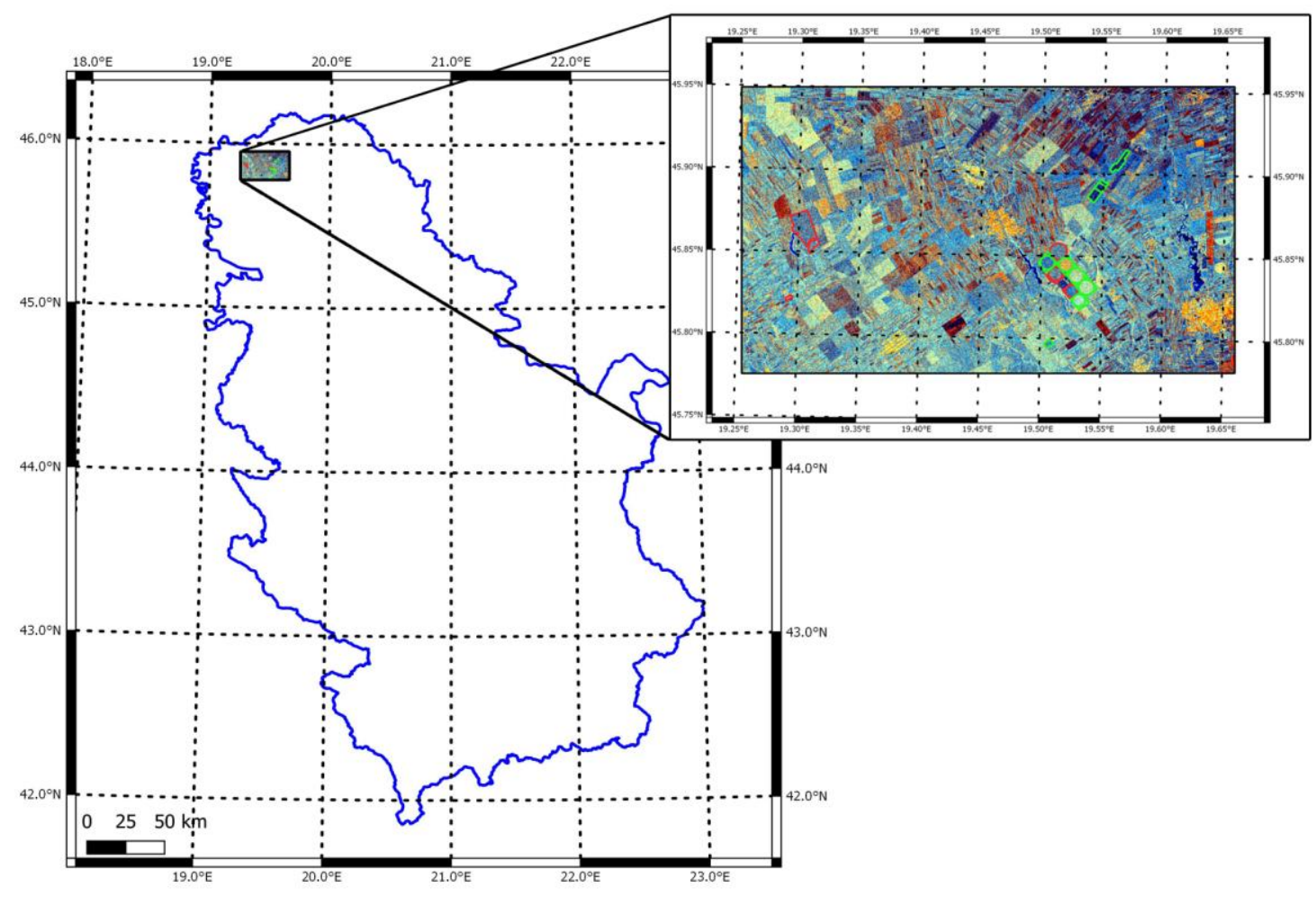

Figure 1. Location of test area within the territory of the Republic of Serbia; 2017 parcels are shown in red and 2018 parcels are shown in green (Copernicus Sentinel data [2017]) 
temperatures caused heat stress in the maize plants. High air temperatures and low amount of rainfall in summer, which is not an uncommon phenomenon due to climate change, considerably affect maize vegetative growth.

During the maize vegetation period from 1 April to 30 September 2018, the precipitation sum of about $398 \mathrm{~mm}$ was recorded, which was $10 \%$ above the multiyear average. However, during maize planting, rather dry and warm weather was observed. Increased daily air temperatures in late April and early May accelerated maize development stages. Weather conditions by the end of spring were favourable, while the period from June to August was more humid and warmer compared with average climatic conditions. The humidity conditions were estimated satisfactory. During tasselling (VT) and silking (R1) stage thermal conditions were appropriate for maize production. The end of July and the beginning of August featured warm, cloudy and unstable weather. September was significantly drier, with precipitation amount below the perennial average. This vegetation season was with favourable weather conditions for maize yields.

All meteorological data, values of temperature and precipitation throughout the season were accessed through the weather service from the web portal of the Republic Hydrometeorological Service of Serbia (RHMSS, www.hidmet.gov.rs) and they refer to Vojvodina province. RHMSS collects weather information for the territory of Serbia and forwards it to the European Centre for Medium-Range Weather Forecast (ECMWF) which collects global weather information.

\section{DATA}

\subsection{Sentinel-1}

Sentinel-1 SAR is the first mission in the European Space Agency Copernicus programme. It is a constellation of two identical satellites, A and B, launched on 3 April 2014 and 25 April 2016 (Potin et al., 2015), respectively. Each satellite carries a single C-band SAR instrument that operates at a central frequency of $5.405 \mathrm{GHz}$ (Yague-Martinez et al., 2016). It supports dual polarization mode of operation and performs acquisition in four different modes, namely Stripmap, Interferometric Wide swath (IW), Extra-Wide swath and Wave mode. For the experiment, data collected in IW mode that images the Earth surface with $250 \mathrm{~km}$ swath width (YagueMartinez et al., 2016) and under incidence angles ranging from $29.1^{\circ}$ to $46.0^{\circ}$ was used.

Sentinel-1 images were downloaded from the Open Access Hub (https://scihub.copernicus.eu/) for the whole calendar years of 2017 and 2018. The total of 102 and 90 images, for 2017 and 2018 calendar year respectively, were downloaded. These images included imagery from both $\mathrm{A}$ and $\mathrm{B}$ satellites of Sentinel-1 mission, for one single orbit numbered 175 . Downloaded images were Level-1 GRD (Ground Range, MultiLook, Detected) product, acquired by the sensor in Interferometric Wide swath (IW) operational mode (Twele et al., 2016). Different number in images per year is due to creation of mosaics of the larger province area that were later subsetted to the area of interest. Due to maintenance work by ESA, around the beginning of June 2017, two images were no longer necessary to cover the province area of Vojvodina and that resulted in different number of images for the two seasons.

\subsection{Weather information}

Hourly temperature and precipitation data for the experiment were collected from (Copernicus Climate Change Service (C3S), 2019). It was selected as a source of weather information instead of RHMSS since it incorporates data that was provided by RHMSS and, moreover, provides global weather information free of charge. C3S data was accessed by using API and Python scripting. Information was acquired from ERA5, which is the fifth-generation atmospheric reanalysis of the global climate made by the ECMWF. Reanalysis combines model data with observations from across the world into globally complete and consistent dataset using the laws of physics. Data assimilation is done with horizontal resolution of $0.25^{\circ} \times 0.25^{\circ}$ (approximately $25 \mathrm{~km}$ at the mid latitudes). From hourly data and for the nearest point to the area of interest, maximum and minimum air temperature and daily amount of precipitation were extracted and used in further analysis. However, the important thing to note is that the observing system has changed drastically over time, and although the assimilation system can resolve data holes, the initially much sparser networks will lead to less accurate estimates. For this reason, ERA5 includes an uncertainty estimate that provides guidance on where products are expected to be more and where less accurate.

\section{METHODOLOGY}

\subsection{Growth stage identification}

Ground truth data related to dates of all development stages of maize were not available for this dataset, but rather just planting and harvesting dates and a hybrid type. The reason for this is post-seasonal experiment design, as well as common practice in Serbian agriculture where the importance of keeping field data records is not yet fully recognized. Due to unavailability of the aforementioned data, identification of growth stages within the seasons was done using an alternative approach. It was based mainly on agronomist domain expertise with an assistance of a weather information archive, reports issued by local agricultural advisory services and available Sentinel-2 imagery. Despite Sentinel-2 imagery being frequently compromised by clouds, agronomy expert was able to use some of the images for visualisation in order to confirm the assumptions.

Maize dynamics in Vojvodina, in general, follow a similar pattern from season to season, with respect to a hybrid and seasonal environmental differences. Planting is done in April, with plant emergence (VE) typically occurring between the first and second week after planting. Approximately 10 days after plant emergence, leaf development stages begin followed by tasselling (VT) that usually happens at the beginning of July, ca. two and a half months after planting. At this stage every plant is at its full height and all leaves have emerged. Tasselling is preferably followed by silking (R1) just a couple of days later, but they can also happen at the same time. Silking is the most critical stage in the development of a maize plant since hot and dry weather at the time could reduce pollination and fertilization, and, consequently, grain yield. Kernel development and grain filling ensue, and the stress impact on kernels reduces as the reproductive period progresses. Reproductive period ends up with physiological maturity (R6). Depending on maturity classes and length of vegetation period, physiological maturity occurs in the period from September up to the end of October. Archive images of different maize growth stages are given in Figure 2. Seasons 2017 and 2018 were typical seasons without extreme deviations in temperature or precipitation, though 2018 was slightly better regarding weather conditions. Estimated 


\begin{tabular}{|c|c|c|c|c|c|c|}
\hline \multicolumn{2}{|c|}{ Approximate maize dynamic scale } & \multicolumn{4}{c|}{ Vegetation season } \\
\cline { 3 - 7 } & Stage & $\begin{array}{c}\text { GDD (literature- } \\
\text { based) }\end{array}$ & $\begin{array}{c}\text { Date (GDD- } \\
\text { based) }\end{array}$ & $\begin{array}{c}\text { Date (domain } \\
\text { knowledge) }\end{array}$ & $\begin{array}{c}\text { Date (GDD- } \\
\text { based) }\end{array}$ & $\begin{array}{c}\text { Date (domain } \\
\text { knowledge) }\end{array}$ \\
\hline & Planting & 0 & \multicolumn{2}{|c|}{$\mathbf{0 5 . 0 4 - 1 0 . 0 4 .}$} & \multicolumn{2}{|c|}{$\mathbf{1 1 . 0 4 - 2 2 . 0 4 .}$} \\
\hline Emergence (VE) & $40-50$ & $16.04-26.04$. & $15.04-20.04$. & $17.04-27.04$. & $18.04-28.04$. \\
\hline Tasselling (VT) & $610-700$ & $26.06-10.07$. & $01.07-15.07$. & $13.06-05.07$. & $01.07-12.07$. \\
\hline Silking (R1) & $680-790$ & & $19.08-05.09$. & $05.09-10.09$. & $08.08-27.08$. & $12.09-22.09$. \\
\hline $\begin{array}{c}\text { Physiological } \\
\text { maturity (R6) }\end{array}$ & $1,300-1,500^{*}$ & \multicolumn{2}{|c|}{$\mathbf{0 7 . 0 9 - 1 2 . 0 9 .}$} & & $\mathbf{1 4 . 0 9 - 2 3 . 0 9 .}$ \\
\hline
\end{tabular}

*estimation can vary up to 1800 degree-days

Table 1. (Left) Approximate maize dynamic scale according to Growing Degree Days reported in literature and (right) estimated dates of each growth stage in 2017 and 2018 season according to the approximate GDD scale and domain knowledge by agronomist. True dates of planting and harvesting are shown in bold.

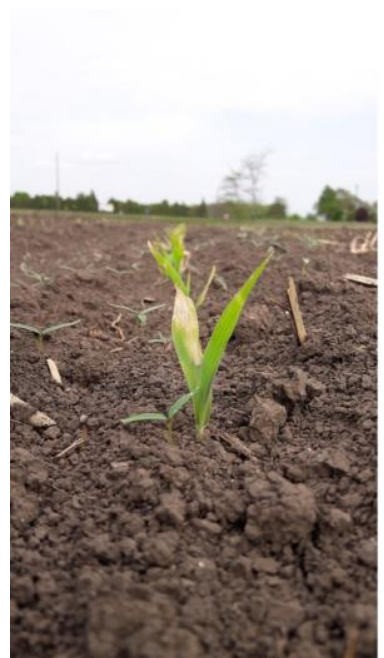

(a)

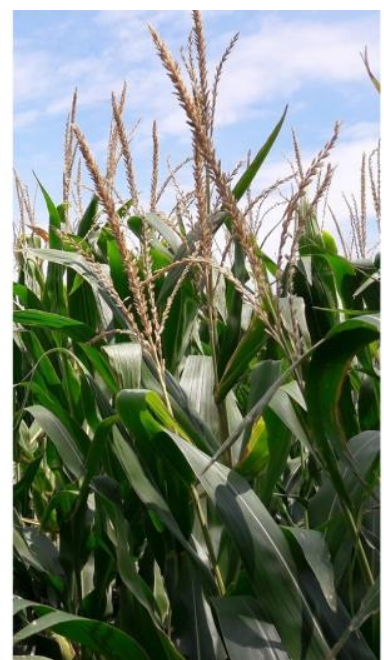

(b)

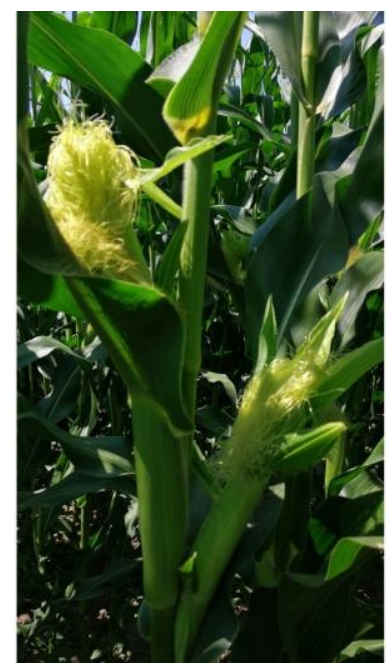

(c)

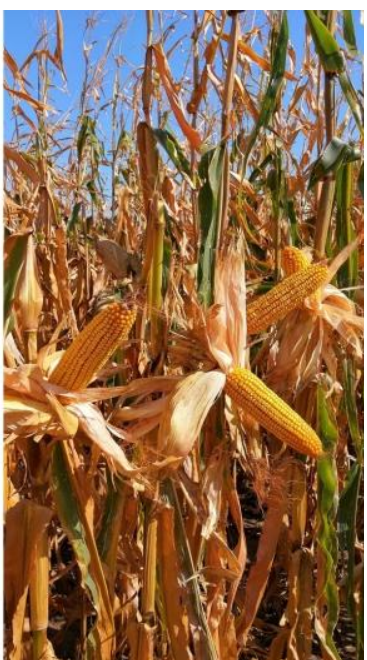

(d)

Figure 2. Archive images of maize growth stages: (a) Emergence, (b) Tasselling, (c) Silking and (d) Physiological maturity

dates of certain growth stages for 2017 and 2018 are given in Table 1.

\subsection{Growing Degree Days}

Growing Degree Days (GDD) is a well-known method used for determining development stages of crops using temperature recordings (Gilmore Jr. and Rogers, 1958; Wang, 1960; Cross and Zuber, 1972; McMaster and Wilhelm, 1997). It is calculated by the formula:

$$
G D D=\frac{T_{\min }+T_{\max }}{2}-T_{\text {base }}
$$

Where

$$
\begin{aligned}
& \mathrm{T}_{\min }=\text { daily minimum temperature } \\
& \mathrm{T}_{\max }=\text { daily maximum temperature } \\
& \mathrm{T}_{\text {base }}=\text { base temperature for a specific crop }
\end{aligned}
$$

For maize, $\mathrm{T}_{\text {base }}=10^{\circ} \mathrm{C}$. The additional constraint seen in the literature when calculating GDD for maize is that if either $\mathrm{T}_{\min }$ or $\mathrm{T}_{\max }$, or both, are below $10{ }^{\circ} \mathrm{C}$, they are substituted with the value of $10{ }^{\circ} \mathrm{C}$ (McMaster and Wilhelm, 1997). Also, if $T_{\max }$ is greater than $30{ }^{\circ} \mathrm{C}$, it is substituted with the value of $30{ }^{\circ} \mathrm{C}$. These constraints are also used in this paper. Starting from zero, accumulated GDD is calculated day after day by adding a daily GDD. After a specific number for accumulated GDD is reached, it is expected for crop to start a next development stage.

Crop development, of either different crop types or different varieties of the same crop, follows different dynamics. Consequently, no single time scale, both in terms of a period of the year and accumulated GDD, is suitable for all cases. For this study an approximate scale was thus set based on the results of the literature search by taking a generalized scope of all stagewise GDD values (Svečnjak et al., 2012; Nielsen and Hinkle 1996; Lee, 2011; Koca and Erekul, 2016; Darby and Lauer, 2006; Jovanović et al., 2002; Nield and Seeley, 1977; Jovanović et al., 2014; Westhoven, 2016; Bayer Group, 2019). Approximation is unfortunately quite general due to lack of relevant information, but it still provides a valuable insight into typical maize dynamics. The scale is presented in Table 1 and accounts for air temperature measurements in degree Celsius, though Fahrenheit-based GDD scales can also be found in the literature. 


\subsection{Sentinel-1 image processing}

In order to obtain information from downloaded satellite images, it was necessary to undertake several preprocessing steps. To avoid time consuming manual preprocessing, an algorithm was developed in Python language utilizing snappy library (SNAP toolbox python interface; European Space Agency, 2018). The algorithm consisted of the following steps: calibration, slice assembly (if necessary), subsetting, speckle filtering, terrain correction and conversion from linear to $\mathrm{dB}$ scale. Calibration was performed in order to obtain normalized cross section $\left(\sigma^{0}\right)$ for $\mathrm{VH}$ and $\mathrm{VV}$ polarisations. In case where two images were necessary to cover the province of Vojvodina, slice assembly was performed to stitch the images. Afterwards, images were cut to the border of Vojvodina. Speckle filtering was done using widely adopted Lee filter with a midsized 5 x 5 kernel being a transitive choice between the smallest $(3 \times 3)$ and other larger kernel sizes ( $7 \times 7,9 \times 9)$ employed in the literature. Terrain correction was accomplished by using bilinear interpolation and SRTM 3 arc-seconds digital elevation model, to create an output image with $10 \mathrm{~m}$ pixel size. In the end, pixel values were converted from linear to $\mathrm{dB}$ scale and the final product saved in TIFF format.

Despite not being as time consuming as manual work would be, processing of each date took about one hour to complete which is the result of weak performance of Python in conjunction with snappy's methods such as writeProduct of class GPF. For this reason, processing steps with altered parameters, such as different kernel sizes or other types of filters, were not tested although they may provide valuable information and are thus intended to be tested in forthcoming experiments. Nevertheless, after completion of the aforementioned preprocessing, total of 60 images per calendar year were obtained with each image size being between $4.1 \mathrm{~GB}$ and $5.3 \mathrm{~GB}$.

Having all the 60 mosaics of Vojvodina per year ready, with calculated $\sigma^{0}$ for $\mathrm{VH}$ and $\mathrm{VV}$ polarisations, the next step was to cut this large area to the extent of the test area in order to reduce the size of the files. This is important because it was followed by calculating cross ratio (CR), the ratio between $\mathrm{VH}$ and $\mathrm{VV}$ (Vreugdenhil et al., 2018), which would ultimately increase the size of the files even more if it was calculated for the whole province of Vojvodina. Since in the preprocessing steps $\sigma^{0}$ was converted to $\mathrm{dB}$ scale, formula for $\mathrm{CR}$ reads:

$$
C R=\sigma_{V H}^{0}-\sigma_{V V}^{0}
$$

Afterwards, for each maize parcel mean values of $\mathrm{VH}, \mathrm{VV}$ and CR bands were calculated for all of the 60 images per season.

\section{RESULTS}

Figure 3a shows seasonal radar backscatter comparison and growth stage periods based on Table 1 in form of time scales, while Figure 3b shows precipitation for 2017 and 2018 season Each line in Figure 3a represents an average backscatter value of the parcels throughout the season. Dates of image acquisitions between the seasons are shifted by one day so 1-to-1 relation can be established without any dispute. Discontinuation at the beginning of October in 2017 season is caused by image unavailability for a specific date.

From the beginning of the year until mid or late April, large differences in VV and VH backscatter can be observed between the two seasons. Their trend is not clear. This is not surprising because the two years featured different weather conditions.
During that period there is no vegetation present in the field, thus all the differences are the result of different soil conditions caused by different amounts of precipitation and soil roughness caused by previous management practice. From late April on, both VV and VH backscatter tend to show similar trends between the seasons, with a steady increase until the beginning of July. This is the result of maize emergence and its intensive growth during the vegetative phase. Certain peaks visible in this period are caused by heavy rains that occurred on the very day of the image acquisition or few days prior (e.g. 17 May and 10 June in 2018 season). By the beginning of July leaves are fully developed and stem elongated, hence the maize reproductive phase begins (VT/R1 stage). From the beginning of July the backscatter stagnates (plateaus visible in the graph) until the beginning of August when it starts to slowly decrease until harvesting. In the period of backscatter stagnation kernel development begins followed by grain filling. When backscatter starts to decrease that is the period when water content in both plant and grain starts to decline (i.e. the ripening period). Again, certain peaks can be noticed probably caused by rainy weather (e.g. 27 August 2018; 20 August 2017).

$\mathrm{CR}$, the ratio between $\mathrm{VH}$ and $\mathrm{VV}$ backscatter, follows a trend similar to those of independent backscatter polarizations in the period from maize emergence to harvesting. For the season 2017 Vreugdenhil et al. (2018) reported that CR increased heavily from 15 May until the end of June and increased furthermore but not that significantly until the second week of July. That is in compliance with findings in this experiment shown in Figure 3a where CR reached its peak for this period on 10 July for the same 2017 season. Then CR stagnates until early or mid-August (the period of kernel development and grain filling), when it starts to decrease due to ripening. Another important characteristic of CR pointed out by Khabbazanet al. (2019) is that it is little or almost not at all influenced by rainy events. This characteristic is also observable in Figure 3 for dates with noticeable rainfall amount such as 17 May, 10 June, 27 August 2018 or 20 August 2017.

According to Table 1, there should be 40-50 GDD accumulated from planting date for maize to emerge. For parcels in 2018 season that corresponds to the period of 17-27 April. By looking at $\mathrm{CR}$ for this time period in Figure 3a, it can be observed that it precedes a period of rising trend in CR values that is caused by leaf development and stem elongation. Hence, it could serve as information about potential crop emergence.

The ending of maize vegetative phase and the beginning of reproductive phase requires between 610 and 790 GDD. This literature-based approximation corresponds to a quite large period in 2018, i.e. from 13 June to 5 July. However, by looking back at Figure 3a, weakening in CR increase can be seen which coincides with the second half of June. Hence, this can be an indicator of change from the vegetative towards the reproductive phase, when no significant change in terms of plant size occur.

Regarding the physiological maturity (R6), 1,300-1,500 is the required value range for GDD according to the literature. In the experiment that corresponds to the period in August. This is, however, too early for maize to reach its R6 stage in Serbia. Typically, it happens at the beginning of September, which in this case corresponds to 1,600-1,750 GDD. This is not unusual because Koca and Erekul (2016) reported ca. 1,700 GDD needed for the physiological maturity of maize in the Mediterranean region of Turkey in 2005 and 2006. In order to address this issue better, more experiments should be conducted 


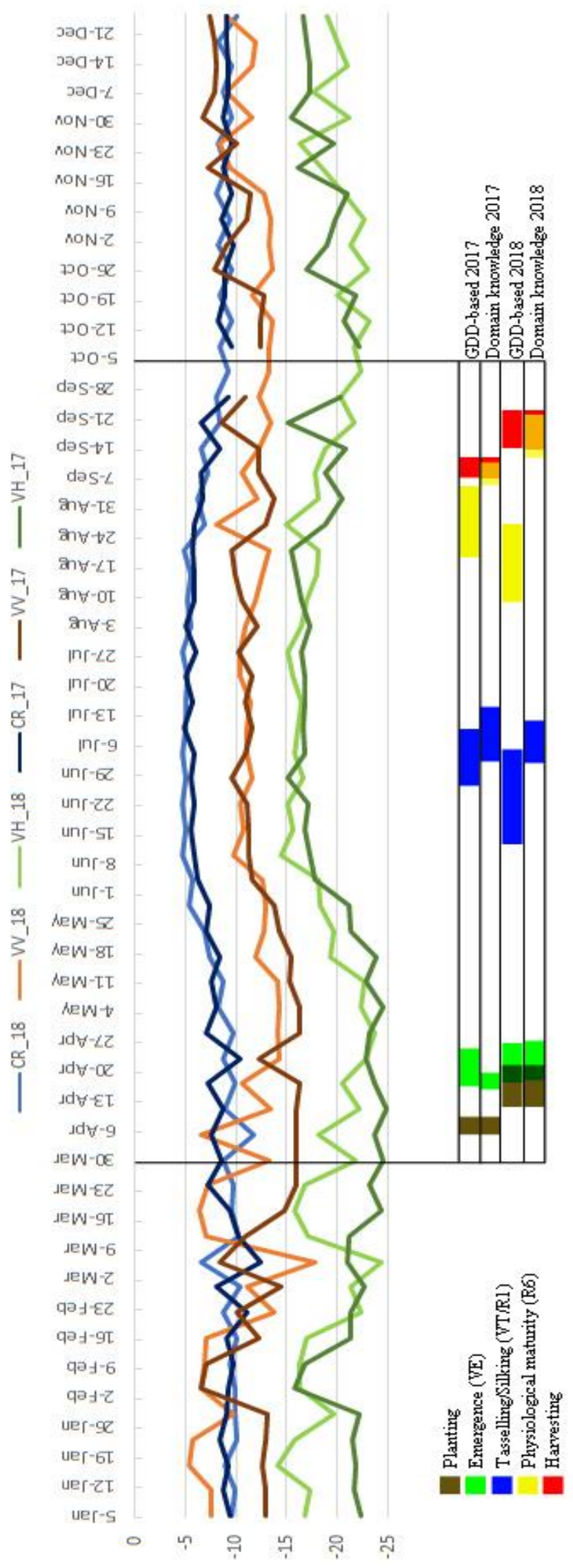

(a)

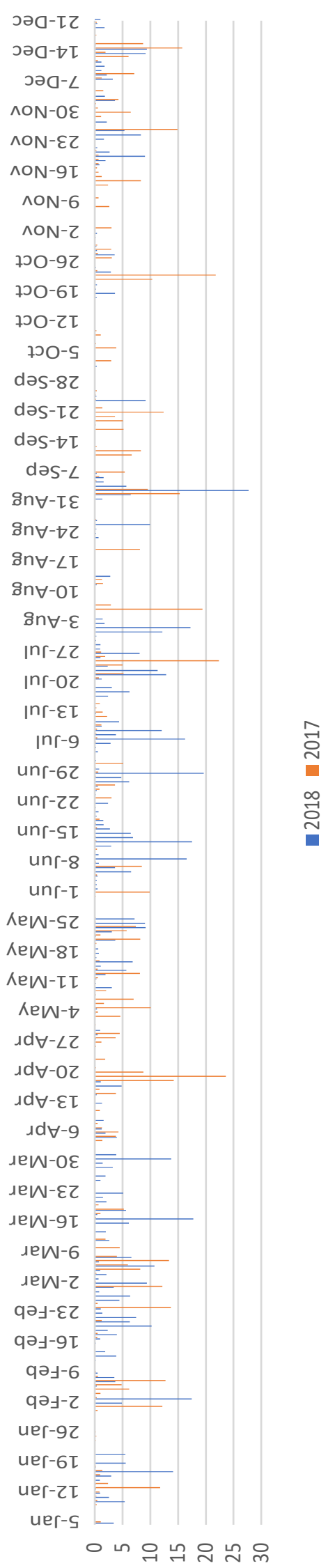

(b)

Figure 3. Season 2017 and 2018 comparison of (a) radar backscatter in $\mathrm{dB}$ and growth stage periods and (b) precipitation in mm 
in future. Decrease in CR (Figure 3a) is noticeable in August and September, but the harvesting date is still very difficult to detect (Khabbazan et al., 2019).

For 2017 season, planting was done from 5 April to 10 April. Accumulation of 40-50 GDD (VE stage) here corresponds to the period of 16-26 April. When looking at Figure 3, a bit more discussion is necessary compared with 2018 season. Namely, the period of 16-26 April 2017 can be interpreted as a period preceding the one with a strong rising trend in CR; hence, it can be potentially identified as the maize emergence period followed by leaf development and stem elongation. However, a trough can be seen on 22 April that can make this interpretation difficult. When there is just bare soil (soil without vegetation), both VV and $\mathrm{VH}$ are equally affected by rain. But when there is some vegetation, $\mathrm{VH}$ is more sensitive to its presence than to soil effect, as opposed to VV polarization that is still greatly sensitive to soil effect. A few days prior to the trough occurrence date, it was raining over several consecutive days (average daily precipitation of $16 \mathrm{~mm}$ ) and that manifested in high peak in VV polarization and loose peak in $\mathrm{VH}$ polarization backscatter. That may actually be a sign of present vegetation, i.e. maize emergence.

Subsequent rising trend in CR when maize is developing in size lasted until 10 July, i.e. the period of maize vegetative phase ending and the beginning of reproductive phase (VT/R1). According to Table 1, 610-790 GDD is necessary for VT/R1 stage and in 2017 that perfectly fits the very end of June and the first half of July (Figure 3a). Thus, GDD method and Sentinel-1 radar backscatter matched regarding growth stage in this case.

The period of physiological maturity, 1,300-1,500 GDD according to the literature search, corresponds to the second half of August and the very beginning of September (Figure 3a). It coincides with the decrease in CR. Due to the early harvest that occurred in the first half of September, a conclusion can be drawn that the physiological maturity may actually have happened in the aforementioned period. Again, harvesting could not be evident in radar backscatter.

\section{CONCLUSION}

Presented results provide an insight into potential of usage of Sentinel-1 backscatter information and Growing Degree Days for maize monitoring. Together they provide a suitable way for distinguishing between certain growth stages of maize throughout the season.

Radar backscatter is greatly influenced by size, shape and orientation of plants and their water content, so moments when changes in these characteristics occur are easily detectable. Nevertheless, exact dates of starting and ending of a certain maize development stage might not be that easy to notice due to other possible influence on backscatter such as rain or uneven development of maize within the parcel. Harvesting is also hard to detect.

GDD is a method for observing maize dynamics by utilizing information on air temperature. Despite being well-known method for decades, it was revealed within this case study that not many references are there in which the test area is an exact or region near the one examined, with similar environmental conditions. Going one step further, even less structured information on behaviour of specific maize varieties is available regarding GDD. Different hybrids of maize have different dynamics during growing period, thus it is not most appropriate to observe maize of different maturity groups as even agents in the analysis. Another important factor for maize development is soil moisture. Sufficient amount of water must be present in soil, otherwise any number of accumulated GDD will not be sufficient itself.

The results showed that leaf development and intensive stem elongation period during the vegetative phase of maize are quite easily noticeable in backscatter time series due to the observable strong increase in backscatter. Also, the period of ripening when backscatter is decreasing due to the plant water content reduction is visible in radar backscatter. The emergence period after planting is difficult to single out without looking at the whole time series of the season and harvesting turned out to be even more demanding concerning that matter. Nevertheless, further research in this area will surely help tackle this issue more successfully. Periods of different growth stages estimated by GDD method were satisfactory since they did match, with certain deviations, estimates made by the local agronomist that were based only on professional experience. The best match was achieved for VE period of maize in 2018 with $83.3 \%$ overlap, whereas the largest mismatch occurred for physiological maturity stage of the same season. Knowing that these estimates were based solely on weather information, GDD derived results provide added value to the radar backscatter information for maize monitoring. With two techniques in hand that have the same goal but completely different approaches, conclusion regarding the goal will have greater significance.

Next experiments should encompass in-field real-time monitoring of environmental conditions that will produce sufficient amount of ground truth data for reliable interpretation of results. This means that weather stations should be installed in the field, as well as soil moisture sensors, that will keep the records related directly to the field conditions, avoiding errors caused by otherwise inevitable approximation methods. Information from radar backscatter and GDD regarding an ongoing growth stage in the field, combined with weather and soil moisture information from installed sensors, will enable farmers to undertake necessary steps in time and tackle issues such as plant stress, thus reaching high yield at the end of season. Keeping the diary of crop dynamics, by recording beginning and ending dates of various stages would not only enable more reliable quality assessment of results obtained by the two presented methods, but also create an opportunity for testing performance of these methods in differentiating additional maize growth stages such as individual leaf development, blister, milk, dough or dent stage. More experiments addressing GDD technique in Vojvodina should be also considered. Structured GDD information on dynamics of different maize varieties would surely bring benefit to everyone interested in maize production. None of the steps presented in the procedure restricts the use of the described method to maize or a specific location. Hence, dynamics of other crop types could be easily monitored in a similar manner all over the world.

\section{ACKNOWLEDGEMENTS}

This work was partially supported by the European Union's Horizon 2020 research and innovation programme grant No. 810775 (DRAGON) and Provincial Secretariat for Higher Education and Scientific Research of Vojvodina through project "Sensor technologies for integrated monitoring of agricultural production". 


\section{REFERENCES}

Abdikan, S., Sekertekin, A., Ustunern, M., Balik Sanli, F. Nasirzadehdizaji, R., 2018: Backscatter analysis using multitemporal Sentinel-1 SAR data for crop growth of maize in Konya basin, Turkey. Int. Arch. Photogramm. Remote Sens. Spat. Inform. Sci., 42, 9-13. doi.org/10.5194/isprs-archivesXLII-3-9-2018.

Bayer Group,

2014 ,

https://www.dekalbasgrowdeltapine.com/en-

us/agronomy/maize-growth-stages-and-growing-degree-

units.html (accessed on 11.12.2019).

Copernicus Climate Change Service (C3S), 2019: ERA5: Fifth generation of ECMWF atmospheric reanalyses of the global climate. Copernicus Climate Change Service Climate Data Store (CDS), https://cds.climate.copernicus.eu/cdsapp\#!/home (accessed on 06.02.2019).

Cross, H.Z., Zuber M.S., 1972: Prediction of flowering dates in maize based on different methods of estimating thermal units, Agron. J., 64, pp. 351-355. doi.org/10.2134/agronj1972.00021962006400030029x.

Darby, H., Lauer, J., 2006: Plant Physiology: Critical Stages in the Life of a Corn Plant, Maize Diagnostic Guide, University of Wisconsin Extension, pp. 17-22.

European Space Agency, 2018: SNAP Toolbox http://step.esa.int/main/toolboxes/snap/ (accessed on 26.11.18).

Gilmore Jr., E.C., Rogers, J.S., 1958: Heat units as a method of measuring maturity in maize, Agron. J., 50, pp. 611-615.

Hrnjak, I., Lukić, T., Gavrilov, M. B., 2014: Aridity in Vojvodina, Serbia, Theor. Appl. Climatol., 115: 323. https://doi.org/10.1007/s00704-013-0893-1.

Jovanović, Ž., Kresović, B., Tolimir, M., Filipović, M., Dumanović, Z., Lopandić, D., 2014: REGIONAL DISTRIBUTION OF THE LATEST ZP MAIZE HYBRIDS GENERATION BY THE HEAT SUMMATION METHOD, Zbornik radova sa XXVIII savetovanja agronoma, veterinara, tehnologa i agroekonomista, Vol. 20. br. 1-4.

Jovanović, Ž., Videnović, Ž., Jovin, P., Vesković, M., Drinić, G., 2002: Rejonizacija ZP hibrida metodom sume toplotnih jedinica, III savetovanje „Nauka, praksa I promet u agraru“, Soko Banja, 10-14.01.2002, Zbornik radova, 127-135.

Khabbazan, S., Vermunt, P., Steele-Dunne, S., RateringArntz, L., Marinetti, C., van der Valk, D., Iannini, L., Molijn, R., Westerdijk, K., van der Sande, C., 2019: Crop Monitoring Using Sentinel-1 Data: A Case Study from The Netherlands. Remote Sens., 11, 1887. doi.org/10.3390/rs11161887.

Koca, Y.O., Erekul, O., 2016: Changes of dry matter, biomass and relative growth rate with different phonological stages of maize, Agriculture and Agricultural Science Procedia, 10, 6775. doi.org/10.1016/j.aaspro.2016.09.015.

Lee, C., 2011: Maize Growth Stages and Growing Degree Days: A Quick Reference Guide, COOPERATIVE EXTENSION SERVICE, UNIVERSITY OF KENTUCKY COLLEGE OF AGRICULTURE.
Liao C., Wang J., Shang J., Huang X., Liu J. and Huffman T., 2018: Sensitivity study of Radarsat-2 polarimetric SAR to crop height and fractional vegetation cover of maize and wheat, Int. J. Remote Sensing, 39, 5, pp. 1475-1490.

McMaster, G.S., Wilhelm, W.W., 1997: Growing degree-days: one equation, two interpretations, Agricultural and Forest Meteorology, 87, 291-300.

Nield, R.E., Seeley, M.W., 1977: Growing degree days predictions for maize and sorghum development and some applications to crop production in Nebraska, Nebr. Agric. Exp. Stn. Res. Bull., 280, Lincoln, NE.

Nielsen, D.C., Hinkle, S.E., 1996: Field evaluation of basal crop coefficients for maize based on growing degree days, growth stage or time, Trans. ASAE, 39, pp. 97-103.

Potin, P., Rosich, B., Miranda, N., Grimont, P., Bargellini, P., Monjoux, E., Martin, J., Desnos, Y.-L., Roeder, J., Shurmer, I., 2015: Sentinel-1 mission status. In Proceedings of the IEEE IGARSS, Milan, Italy, 26-31 July 2015, pp. 2820-2823.

Statistical Office of the Republic of Serbia, 2019a: Realized production of wheat and early fruit and expected yields of late crops, fruit and grapes, Statistical release PO16, Number 260, Year LXIX, 25.09.2019, ISSN 0353-9555.

Statistical Office of the Republic of Serbia, 2019b: MONTHLY STATISTICAL BULLETIN 08/2019, ISSN 2217-2092.

Svečnjak, Z., Barenić, S., Varga, B., Jareš, D., 2012: GROWING DEGREE DAYS FROM PLANTING TO PHYSIOLOGICAL MATURITY OF MAIZE HYBRIDS BELONGING TO FAO 200-500 GROUPS, Sjemenarstvo, 29(1-2): 25-36.

Twele, A., Cao, W., Plank, S., Martinis, S., 2016: Sentinel-1based flood mapping: A fully automated processing chain. Int. J. Remote Sens., 37, 2990-3004. doi.org/10.1080/01431161.2016.1192304.

Veloso, A., Mermoz, S., Bouvet, A., Toan, T. L., Planells, M., Dejoux, JF., Ceschia, E., 2017: Understanding the temporal behavior of crops using Sentinel-1 and Sentinel-2-like data for agricultural applications, Remote Sensing of Environment, 199, 415-126. doi.org/10.1016/j.rse.2017.07.015.

Vreugdenhil, M., Wagner, W., Bauer-Marschallinger, B., Pfeil, I., Teubner, I., Rüdiger, C., Strauss, P., 2018: Sensitivity of Sentinel-1 Backscatter to Vegetation Dynamics: An Austrian Case Study. Remote Sens., 10, 1396. doi.org/10.3390/rs10091396.

Wang, J.Y., 1960: A critique of the heat unit approach to plant response studies, Ecology, 41 (4), pp. 785-790.

Westhoven, A., 2016: Growing Degree Units (GDU's) for Maize Growth Development, AgriGold, St. Francisville, IL 62460, http://www.agrigold.com/Universal/Articles/GrowingDegree-Units-(GDU\%E2\%80\%99s)-for-Maize-Growth-D-(4)/ (accessed on 11.12.2019).

Yague-Martinez, N., Prats-Iraola, P., Rodriguez Gonzalez, F., Brcic, R., Shau, R., Geudtner, D., Eineder, M., Bamler, R., 2016: Interferometric processing of Sentinel-1 TOPS data, IEEE Trans. Geosci. Remote Sens., 54, pp. 2220-2234. 